\title{
Potentially inappropriate medications in hospitalized older patients: a cross-sectional study using the Beers 2015 criteria versus the 2012 criteria
}

This article was published in the following Dove Press journal:

Clinical Interventions in Aging

12 October 2017

Number of times this article has been viewed

\author{
Xiaolin Zhangl,* \\ Shuang Zhou ${ }^{2, *}$ \\ Kunming $\operatorname{Pan}^{2}$ \\ Xinran $\mathrm{Li}^{2}$ \\ Xia Zhao ${ }^{2}$ \\ Ying Zhou ${ }^{2}$ \\ Yimin Cui ${ }^{2}$ \\ Xinmin Liu' \\ 'Department of Geriatrics, \\ ${ }^{2}$ Department of Pharmacy, Peking \\ University First Hospital, Beijing, \\ China
}

*These authors contributed equally to this work
Correspondence: XinMin Liu Department of Geriatrics, Peking University First Hospital, No.8 of Xishiku street, Xicheng District, Beijing 100034,

China

Tel +86 I0 66II 0802

Email Ixm2128@।63.com
Aim: Polypharmacy and potentially inappropriate medications (PIMs) are prominent prescribing issues in elderly patients. The purpose of the study was to investigate the prevalence of PIMs identified by the Beers 2015 and 2012 criteria in older patients in China and identify the correlates of PIMs.

Methods: This retrospective, cross-sectional study was conducted at Peking University First Hospital. The Beers 2015 and 2012 criteria were applied to evaluate PIMs among hospitalized patients. The associations between PIM use and independent variables were analyzed by logistic regression. The differences between PIM use according to Beers 2012 and 2015 criteria were calculated using chi-squared and kappa tests.

Results: A total of 456 patients were analyzed; 244 (53.5\%) and 204 (44.7\%) patients had at least one PIM identified by the Beers 2015 and 2012 criteria, respectively. The most frequent PIMs were proton-pump inhibitors (PPIs), benzodiazepines, and benzodiazepine receptor agonists according to the Beers 2015 criteria. PIMs identified by the Beers 2015 criteria were associated with excessive polypharmacy (OR 1.864, 95\% CI 1.210-2.871), a Barthel index $\leq 60$ (OR $1.935,95 \%$ CI 1.056-3.546), and the length of stay (OR 1.066, 95\% CI 1.037-1.097). PIM use increased significantly between two criteria (chi-squared test, $P<0.001$ ), but good accordance was found between the previous and updated criteria (kappa test $0.782, P<0.001$ ).

Conclusion: Our study showed a high prevalence of PIM use in China, which was associated with various correlates. The Beers 2015 criteria detected significantly more PIMs than the 2012 criteria due to the inclusion of PPIs.

Keywords: Beers criteria, inappropriate prescription, polypharmacy

\section{Introduction}

The physiological alterations related to aging, such as changes in body composition and reductions in kidney and liver function, can significantly change pharmacokinetic and pharmacodynamic properties. Alteration of age-related pharmacokinetics and pharmacodynamics predisposes older adults to drug-related problems, such as adverse drug reactions (ADRs), drug-drug interactions, and drug-disease interactions. ${ }^{1}$ Potentially inappropriate medications (PIMs) can be defined as drugs for which use among older adults should be avoided due to the high risk of adverse reactions for this population and/or insufficient evidence of their benefits when safer and equally or more effective therapeutic alternatives are available. ${ }^{2}$ Inappropriate medication prescribing in older adults has become a public health concern due to its high prevalence, ${ }^{3}$ associated negative outcomes, including ADRs, morbidity, hospitalization, health services use, and increased costs. ${ }^{4-9}$ 
To prevent PIM use, experts have begun to address this issue and devise screening tools to assess the extent of PIMs and guide clinical practice in older adults. One of the first consensuses of experts was achieved by Beers et al in the USA in $1991,{ }^{10}$ which was proposed by an expert panel using the Delphi method. The American Geriatrics Society Beers Criteria for PIM Use in Older Adults is an explicit list of PIMs that should be avoided in older adults in general and in people with certain diseases or syndromes, prescribed at a reduced dosage or used with caution or careful monitoring. ${ }^{11}$ The Beers criteria are one of the most frequently consulted sources and were updated in 2003 and 2012. The changes in the 2015 update were not as extensive as those of the previous updates; the following two major components were added: 1) drugs for which dose adjustment is required based on kidney function and 2) drug-drug interactions. ${ }^{12}$ With the increasing use of the Beers criteria as a quality-of-care measure, a need exists to strengthen the predictive validity of the Beers criteria in all health care settings. ${ }^{13}$

However, to our knowledge, no data have shown the prevalence of PIMs identified by the updated version of the Beers criteria in China and no studies have compared the 2012 and 2015 versions to detect PIMs. Therefore, the objectives of the present study were 1) to assess the prevalence of PIMs using the Beers 2012 and 2015 criteria; 2) to explore related risk factors for PIMs according to the 2015 criteria; and 3) to compare the prevalence of differences and the accordance of PIMs between the 2012 and 2015 criteria.

\section{Methods}

\section{Setting and sample}

This retrospective, cross-sectional study was conducted at Peking University First Hospital, a 1,500 bed tertiary care teaching hospital in China. The Department of Geriatrics cares for aging patients and patients with age-related diseases (such as cardiocerebral vascular disease, respiratory disease, and digestive disease). Hospitalized patients in the geriatric department aged $\geq 65$ years were enrolled from May 2015 to December 2015. If a patient had more than one visit for a prescription refill within the study period, only the first occurrence was used in the analyses. Patients without any medications were excluded. The study protocol was approved by the Ethics Committee of Peking University First Hospital. Each participant provided written informed consent to be included in the study.

\section{Data collection and measures}

Data including age, gender, primary diagnosis, comorbidities, prescribed drugs and precise dosages, length of stay,
ADRs, Barthel index, estimated glomerular filtration rate (eGFR), and prognosis (discharge or death) were extracted from patient medical records. The eGFR was calculated using the modified, abbreviated Modification of Diet in Renal Disease equations based on Chinese patients. The Charlson Comorbidity Index (CCI) was calculated for each patient. The Beers 2015 and 2012 criteria were adopted to determine the use of PIMs in the study patients.

\section{Statistical analysis}

All analyses were conducted using SPSS version 23.0; a two-tailed value of $P<0.05$ was considered statistically significant. Continuous data are expressed as the mean $\pm \mathrm{SD}$, nonparametric variables are expressed as the median and interquartile range (IQR), and categorical data are expressed as frequencies. The patients were divided into PIM (at least one PIM) and non-PIM (without any PIMs) groups. A chisquared test was applied to compare dichotomous variables between groups, and Fisher's exact test was used when expected cell counts were below five. Student's $t$-test or a nonparametric test was applied to compare the mean or median, respectively, of continuous variables. Multivariate logistic regression was used to examine factors related to PIMs according to the Beers 2015 criteria. The chi-squared test and kappa test were used to evaluate the prevalence of differences and accordance of the two criteria, respectively.

\section{Results}

\section{Demographics of participants}

Table 1 describes the characteristics of the study population. A total of 611 participants aged 65 years or older were included in the present study. Of these, 140 participants were excluded for being repeatedly admitted to the hospital and 15 participants were excluded as no medication was prescribed during hospitalization. Among the remaining 456 patients, the average age was $81.8 \pm 7.8$ years (range 65-103 years) and $334(73.2 \%)$ patients were male. A total of 70 patients (15.4\%) had a Barthel index of $\leq 60$, which indicated physical disability. The prevalence of elderly patients who were regularly prescribed $\geq 10$ drugs was $37.9 \%$. The median length of hospital stay and CCI were 14 days (IQR 9-21) and two points (IQR 1-3), respectively. Of all patients, 13 ADRs occurred, and four events were due to PIMs. Long-term usage of zolpidem tartrate tablets that leads to abnormal behavior and sleep disorders, taking dabigatran that leads to gastrointestinal bleeding, taking amiodarone that leads to elevated transaminase levels, and taking diuretics that caused orthostatic hypotension and falls during hospitalization were the four ADRs. 
Table I Baseline and clinical characteristics of 456 older adults as identified by the Beers criteria of 2015 and 2012

\begin{tabular}{|c|c|c|c|c|c|c|c|}
\hline \multirow[t]{2}{*}{ Characteristics } & \multirow{2}{*}{$\begin{array}{l}\text { Total } \\
(n=456)\end{array}$} & \multicolumn{2}{|c|}{ Beers 2015 criteria } & \multirow[t]{2}{*}{$P$-value } & \multicolumn{2}{|c|}{ Beers 2012 criteria } & \multirow[t]{2}{*}{$P$-value } \\
\hline & & $\begin{array}{l}\text { PIM } \\
(n=244)\end{array}$ & $\begin{array}{l}\text { Non-PIM } \\
(n=2 \mid 2)\end{array}$ & & $\begin{array}{l}\text { PIM } \\
(n=204)\end{array}$ & $\begin{array}{l}\text { Non-PIM } \\
(n=252)\end{array}$ & \\
\hline Instances of PIM per person (mean \pm SD) & & $1.7 \pm 0.9$ & & & $1.5 \pm 0.8$ & & \\
\hline Age, years $($ mean $\pm S D)$ & $81.8 \pm 7.8$ & $83.2 \pm 7.7$ & $80.3 \pm 7.6$ & $<0.001$ & $83.6 \pm 7.7$ & $80.4 \pm 7.5$ & $<0.001$ \\
\hline \multicolumn{8}{|l|}{ Gender } \\
\hline Male, N (\%) & $334(73.2)$ & $170(69.7)$ & $164(77.4)$ & & $142(69.6)$ & $192(76.2)$ & \\
\hline Female, N (\%) & $122(26.8)$ & $74(30.3)$ & $48(22.6)$ & 0.064 & $62(30.4)$ & $60(23.8)$ & 0.114 \\
\hline \multicolumn{8}{|l|}{ Barthel score } \\
\hline$\leq 60, N(\%)$ & $70(15.4)$ & $52(21.3)$ & I8 (8.5) & & $46(22.5)$ & $24(9.5)$ & \\
\hline$>60, \mathrm{~N}(\%)$ & $386(84.6)$ & $192(78.7)$ & $194(9 \mid .5)$ & $<0.001$ & $158(77.5)$ & $228(90.5)$ & $<0.001$ \\
\hline \multicolumn{8}{|l|}{ Prescribed medications } \\
\hline$<10, N(\%)$ & $283(62.1)$ & $125(5 \mid .2)$ & I 58 (74.5) & & $99(48.5)$ & $184(73.0)$ & \\
\hline$\geq 10, N(\%)$ & $173(37.9)$ & $119(48.8)$ & $54(25.5)$ & $<0.001$ & $105(51.5)$ & $68(27.0)$ & $<0.001$ \\
\hline Length of stay in hospital, days, median (IQR) & $14(9-2 \mid)$ & $17(11-24)$ & II (8-18) & $<0.001$ & $17(\mid 1-24)$ & $12(8-19)$ & $<0.001$ \\
\hline eGFR $($ mean $\pm S D)$ & $69.1 \pm 23.7$ & $67.3 \pm 24.2$ & $71.1 \pm 23.1$ & 0.081 & $67.1 \pm 24.9$ & $70.7 \pm 22.6$ & 0.090 \\
\hline $\mathrm{CCl}$ (points), median (IQR) & $2(I-3)$ & $2(I-4)$ & $2(I-3)$ & 0.008 & $2(1-4)$ & $2(I-3)$ & 0.177 \\
\hline Adverse drug reaction, $\mathrm{N}(\%)$ & $13(2.8)$ & $8(3.3)$ & $5(2.4)$ & 0.771 & $7(3.4)$ & $6(2.4)$ & 0.503 \\
\hline Fall in hospital, $\mathrm{N}(\%)$ & $\mathrm{I}(0.2)$ & I (0.4) & $0(0.0)$ & 1.000 & $0(0.0)$ & I $(0.4)$ & 1.000 \\
\hline Death in hospital, N (\%) & $4(0.9)$ & $2(0.8)$ & $2(0.9)$ & 1.000 & I $(0.5)$ & $3(0.2)$ & 0.632 \\
\hline
\end{tabular}

Abbreviations: $\mathrm{CCl}$, Charlson Comorbidity Index; eGFR, estimated glomerular filtration rate; IQR, interquartile range; PIM, potentially inappropriate medication; $\mathrm{SD}$, standard deviation.

\section{PIM use}

According to the Beers 2015 criteria, our study identified 244 of the 456 patients using PIMs. Table 2 shows that 407 medications were detected, resulting in $1.7 \pm 0.9$ PIMs per patient. The distribution of PIMs in our sample according to the Beers 2015 criteria was as follows: 265 cases were identified in which patients were using medications that should be avoided in older patients; the most frequent PIMs were proton-pump inhibitors (PPIs) (111/265, 41.9\%), benzodiazepines $(79 / 265,29.8 \%)$, and benzodiazepine receptor agonist hypnotics $(22 / 265,8.3 \%)$. These three PIMs accounted for $80 \%$ of the medications that should be avoided. Additionally, 13 patients were taking medications to be avoided in older adults with certain diseases and syndromes that the drugs can exacerbate and 122 patients were taking drugs to be used with caution, mostly including diuretics $(89 / 122,73.0 \%)$ and dabigatran $(25 / 122,20.5 \%)$. Spironolactone $(2 / 6,33.3 \%)$ and famotidine $(4 / 6,66.7 \%)$ were drugs to be avoided for patients with reduced kidney function. One case of antidepressant use combined with $\geq 2$ central nervous system-active drugs was detected as a drugdrug interaction.

Thirteen ADRs occurred in our participants. Of these, four events were due to PIMs, including digoxin (1), zolpidem (2), and dabigatran (1). Other ADRs were due to aspirin, zoledronate, iodine contrast medium, chemotherapeutics, antibiotics, and angiotensin-converting enzyme inhibitors.

\section{Beers criteria of 2012 versus 2015}

A total of 204 patients were identified as using PIMs according to the Beers 2012 criteria. Table 3 shows 18 PIMs detected by the 2012 criteria that were removed from the 2015 criteria. In addition, 111 PIMs were added to the Beers 2015 criteria that were not included in the classification of the 2012 criteria. Notably, these were nearly all PPIs. Benzodiazepines were replaced by PPIs as the most frequent PIMs.

The use of Beers 2015 criteria yielded significantly higher PIM use within our sample than the 2012 criteria (55.3 versus $44.7 \%$, respectively, $P<0.001$ ), as shown in Table 4 . A kappa test showed good accordance among the previous and updated criteria (kappa $>0.7, P<0.001$ ).

Our findings suggest that the differences between the 2012 and 2015 criteria were due to PPIs, a new list of drugs to be avoided or reduced according to kidney function and PIMs resulting in drug-drug interactions.

\section{Factors associated with PIM use}

According to the Beers 2015 criteria, the PIM group exhibited significant differences regarding age $(P<0.001)$, a Barthel index of $\leq 60(P<0.001), 10$ or more prescribed medications $(P<0.001)$, length of hospital stay $(P<0.001)$, and CCI points $(P=0.008)$ compared to the non-PIM group.

In the multivariate logistic regression model, based on the Beers 2015 criteria, PIM use was associated with 
excessive polypharmacy ( $\geq 10$ prescribed medications) (OR 1.864, 95\% CI 1.210-2.871), a Barthel index of $\leq 60$ (OR 1.935, 95\% CI 1.056-3.546), and length of hospital stay (OR 1.066, 95\% CI 1.037-1.097), as shown in Table 5.

Table 2 Most commonly encountered PIMs according to the Beers 2015 criteria

\begin{tabular}{|c|c|c|c|}
\hline \multicolumn{4}{|c|}{ Beers 20 I 5 criteria PIMs $(N=407)$} \\
\hline $\begin{array}{l}\text { Drugs that should be } \\
\text { avoided }\end{array}$ & & $n=265$ & $\%$ \\
\hline \multirow[t]{2}{*}{ Anticholinergics } & Chlorpheniramine & 3 & I.I \\
\hline & Promethazine & 1 & 0.4 \\
\hline Antispasmodics & Belladonna alkaloids & 2 & 0.8 \\
\hline \multirow[t]{4}{*}{ Cardiovascular } & Doxazosin & 14 & 5.3 \\
\hline & Terazosin & 14 & 5.3 \\
\hline & Digoxin & 8 & 3.0 \\
\hline & Amiodarone & 4 & 1.5 \\
\hline Antipsychotics & Olanzapine & 4 & 1.5 \\
\hline Benzodiazepines & $\begin{array}{l}\text { Alprazolam (I), estazolam } \\
\text { (63), lorazepam ( } 10) \text {, } \\
\text { clonazepam (4), and } \\
\text { diazepam (I) }\end{array}$ & 79 & 29.8 \\
\hline $\begin{array}{l}\text { Benzodiazepine receptor } \\
\text { agonist hypnotics }\end{array}$ & $\begin{array}{l}\text { Eszopiclone (4) and } \\
\text { zolpidem (18) }\end{array}$ & 22 & 8.3 \\
\hline \multirow[t]{2}{*}{ Gastrointestinal } & Metoclopramide & 2 & 0.8 \\
\hline & Proton-pump inhibitors & 111 & 41.9 \\
\hline NSAIDs & Ibuprofen & $\mathrm{I}$ & 0.4 \\
\hline $\begin{array}{l}\text { Drug-disease or drug- } \\
\text { syndrome interaction }\end{array}$ & & $n=13$ & $\%$ \\
\hline Dementia or cognitive & Estazolam & 3 & 23.1 \\
\hline impairment & Zolpidem & 5 & 38.5 \\
\hline History of falls or & Midazolam & 1 & 7.7 \\
\hline fractures & Diazepam & 1 & 7.7 \\
\hline History of gastric or & Ibuprofen & 2 & 15.4 \\
\hline duodenal ulcers & Lysine acetylsalicylate & 1 & 7.7 \\
\hline \multirow{8}{*}{$\begin{array}{l}\text { Drugs that should be } \\
\text { used with caution }\end{array}$} & & $n=122$ & $\%$ \\
\hline & $\begin{array}{l}\text { Aspirin for primary } \\
\text { prevention of cardiac events }\end{array}$ & I & 0.8 \\
\hline & Dabigatran & 25 & 20.5 \\
\hline & Diuretics & 89 & 73.0 \\
\hline & Carbamazepine & 1 & 0.8 \\
\hline & Mirtazapine & 4 & 3.3 \\
\hline & Olanzapine & 1 & 0.8 \\
\hline & Carboplatin & I & 0.8 \\
\hline \multirow{4}{*}{$\begin{array}{l}\text { Drugs that should be } \\
\text { avoided or reduced } \\
\text { with impaired kidney } \\
\text { function }\end{array}$} & & $n=6$ & $\%$ \\
\hline & & & \\
\hline & Spironolactone & 2 & 33.3 \\
\hline & Famotidine & 4 & 66.7 \\
\hline \multirow{3}{*}{$\begin{array}{l}\text { Drug-drug interactions } \\
\text { that should be avoided }\end{array}$} & & $n=I$ & $\%$ \\
\hline & & & \\
\hline & $\begin{array}{l}\text { Flupentixol/melitracen, } \\
\text { paroxetine with zolpidem, } \\
\text { and olanzapine }\end{array}$ & 1 & 100 \\
\hline
\end{tabular}

Abbreviations: NSAIDs, nonsteroidal anti-inflammatory drugs; PIM, potentially inappropriate medications.
Table 3 Medication changes in Beers 2015 criteria since Beers 2012 criteria

\begin{tabular}{|c|c|c|}
\hline Removed & & $\begin{array}{l}\text { Number of } \\
\text { drugs (N) }\end{array}$ \\
\hline $\begin{array}{l}\text { Antiarrhythmic drugs } \\
\text { as first-line treatment } \\
\text { for atrial fibrillation }\end{array}$ & Propafenone & 4 \\
\hline Chronic constipation & $\begin{array}{l}\text { Diltiazem (3), } \\
\text { chlorpheniramine (I), } \\
\text { diphenhydramine (I), } \\
\text { belladonna (2), and } \\
\text { hyoscyamine (I) }\end{array}$ & 8 \\
\hline Lower urinary tract & Inhaled anticholinergic drugs & 6 \\
\hline Added & & $\mathbf{N}$ \\
\hline Proton-pump inhibitors & Proton-pump inhibitors & $1 \mathrm{II}$ \\
\hline
\end{tabular}

\section{Discussion}

The present study compared the prevalence of PIMs and their association with related factors between two versions of the Beers criteria in elderly inpatients in China. The major findings were as follows: 1) relatively high PIM prevalence rates were detected, 53.5 and $44.7 \%$, by the Beers 2015 and 2012 criteria, respectively; 2) the prevalence of PIM use identified according to the previous criteria and the updated criteria exhibited significant differences but had good concordance; 3) benzodiazepines were replaced by PPIs as the most frequent PIMs; and 4) according to the Beers 2015 criteria, PIM use was associated with excessive polypharmacy, a Barthel index of $\leq 60$, and the length of the hospital stay.

The prevalence of PIMs in this study was apparently higher than that found in studies conducted in other countries. In a study conducted in a psychiatric hospital in the Netherlands, which was more likely to detect PIMs with psychotropic drugs, a low prevalence of PIMs (47\%) was found in elderly patients evaluated by the Beers 2012 criteria. ${ }^{11}$ Another noteworthy study was a US retrospective cohort study that included 38,250 inpatients and reported that the prevalence of PIMs evaluated by the Beers 2012 criteria decreased from $37.6 \%$ in 2007 to $34.2 \%$ in $2012 .{ }^{14}$ A crosssectional analysis that included 567 Belgian patients aged

Table 4 Beers 2015 and 2012 criteria concordance

\begin{tabular}{|c|c|c|c|c|}
\hline & \multicolumn{2}{|c|}{ Beers 2015 listed } & \multirow[t]{2}{*}{ Total } & \multirow[t]{2}{*}{$P$-value } \\
\hline & $\begin{array}{l}\text { PIM } \\
\text { patients }\end{array}$ & $\begin{array}{l}\text { Non-PIM } \\
\text { patients }\end{array}$ & & \\
\hline \multicolumn{5}{|c|}{ Beers 2012 listed } \\
\hline PIM patients & 199 (43.6\%) & $5(1.1 \%)$ & $204(44.7 \%)$ & $<0.00 \mathrm{I}^{\mathrm{a}}$ \\
\hline Non-PIM patients & $45(9.9 \%)$ & $207(45.4 \%)$ & 252 (55.3\%) & $\begin{array}{l}<0.00 \mathrm{I}^{\mathrm{b}} \\
(\text { Kappa }=0.782)\end{array}$ \\
\hline Total & 244 (53.5\%) & $212(46.5 \%)$ & 456 & \\
\hline
\end{tabular}

Notes: abased on the chi-squared test. 'based on kappa test. Abbreviation: PIM, potentially inappropriate medication. 
Table 5 Multivariate analysis of variables independently associated with potentially inappropriate medication use according to the Beers 2015 criteria

\begin{tabular}{llll}
\hline Variables & OR & $\mathbf{9 5 \% ~ C l ~}$ & P-value \\
\hline $\begin{array}{l}\text { Excessive polypharmacy } \\
\text { (prescribed medications } \geq 10)\end{array}$ & 1.864 & $(1.210-2.87 I)$ & 0.005 \\
$\begin{array}{l}\text { Barthel index } \leq 60 \\
\text { Length of stay }\end{array}$ & 1.935 & $(1.056-3.546)$ & 0.033 \\
\hline
\end{tabular}

80 years and older reported that PIMs classified as drugs to avoid according to the Beers 2012 were used in $32 \%$ of the patients and PIMs labeled to be used with caution were found in $45 \%$ of the patients. ${ }^{15}$

The Beers criteria have been very widely used in China. The prevalence of PIMs in this study was comparable to that found in other studies conducted in China. One study that evaluated 1,796 hospitalized Chinese elderly patients reported that $53.2 \%$ of patients used at least one PIM according to the 2012 Beers criteria. ${ }^{16}$ Another study completed by the same research team evaluated 6,337 hospitalized Chinese elderly patients and reported that the prevalence of PIMs detected by the Beers 2012 criteria was $72.48 \% .^{17}$

The possible reasons for the higher prevalence of PIMs in China may be as follows: 1) older Chinese patients are unwilling to try nondrug methods of therapy, such as exercise and psychological approaches; 2) physicians in China, even geriatricians, lack necessary knowledge of polypharmacy and PIMs in elderly adults; and 3) a lack of intervention by clinical pharmacists based on efficient screening tools..$^{14,18}$

The 2015 revision of Beers criteria aimed to provide a comprehensive systematic review and grading of evidence regarding drug-related problems and ADRs in older adults. Notable changes included drug-drug interactions and medications that require dose reduction or avoidance with renal impairment. ${ }^{11}$ In our study, spironolactone and famotidine were to be used with caution or avoided in patients with reduced kidney function. Patients with a creatinine clearance of $<30 \mathrm{~mL} / \mathrm{min}$ are recommended to avoid using spironolactone, which may increase potassium levels. Spironolactone is a potassiumsparing diuretic that increases serum potassium levels, as it blocks the potassium secreting effect of aldosterone in the distal tubulus. Spironolactone is widely used in China, and hyperkalemia is a severe and even fatal consequence. ${ }^{19}$ A standard dose of spironolactone poses a great risk to patients with renal insufficiency. ${ }^{20}$

Consistent with most studies, the most common PIMs identified by the 2012 criteria were benzodiazepines. According to the Beers 2015 criteria, the most frequently prescribed PIMs were PPIs. The use of PPIs for $>2$ months is not recommended except in specific circumstances when long-term acid suppression therapy is indicated. This was a new addition to the Beers criteria, and 111 related cases were detected in our study. PPIs are generally well tolerated with short-term treatment, but prolonged exposure to PPIs can cause Clostridium difficile-associated diarrhea ${ }^{21}$ and has also been associated with falls and fractures. ${ }^{22}$ Additional concerning risks of PPIs treatment in the elderly, although not as well supported through clinical evidence, include chronic kidney disease, acute interstitial nephritis, vitamin B12 deficiency, rhabdomyolysis, anemia, thrombocytopenia, and hypomagnesemia. ${ }^{23,24}$ Our study analyzed medications during hospitalization, which was often $<2$ months. PIM use of PPIs was defined as using PPIs in the hospital and recommendations to continue use after discharge from the hospital without specific indications. This may be a possible reason for the high prevalence of PIM use of PPIs. The high prevalence of PPIs' use in the elderly must be considered. Clinicians should value opportunities to reduce doses or deprescribe PPIs for long-term care, particularly among those with risk factors for unnecessary medication use.

This study revealed that the most common PIMs were benzodiazepines, according to the Beers 2012 criteria, which ranked only second to PPIs' use according to the Beers 2015 criteria. This is consistent with other studies of hospitalized older patients. ${ }^{17,25}$ A potential reason for the high prevalence of benzodiazepine use is that with aging, a greater number of older adults are troubled with insomnia and depression. To solve this problem, psychoactive drugs are more frequently prescribed to older adults by physicians, thereby causing PIM use. Benzodiazepines and benzodiazepine receptor agonists are known to increase the risk of falls and hip fractures, especially in individuals with a prior history of falls. Nonpharmacological options are recommended to treat insomnia initially, including sleep hygiene combined with behavioral interventions. ${ }^{26}$ Even if nonpharmacological therapy is difficult to perform in hospitalized patients, avoiding long-term use of benzodiazepines and conducting rehabilitation of sleep in community health institutions should be applied. Recently, some authors have focused on reducing benzodiazepine prescriptions. Direct-to-consumer education by physicians or pharmacists has been confirmed as being more effective than usual care for reducing the overuse of benzodiazepines. ${ }^{27}$

A significant factor associated with PIMs was the regular prescription of $\geq 10$ medications, even after adjusting for confounding variables. A strong association between polypharmacy and PIMs has been reported in many studies. However, no consensus exists on the minimum number of regular medications 
that need to be prescribed to be considered polypharmacy. The majority of studies have used $\geq 5$ prescribed drugs as the threshold for polypharmacy, and $\geq 10$ drugs are considered excessive polypharmacy. ${ }^{28}$ Increasing the number of combinations of medications increases the risk of inappropriate prescriptions and ADRs. ${ }^{29}$ A systematic review ${ }^{30}$ using the Beers criteria as an instrument to assess the appropriateness of prescriptions indicated that approximately one in five prescriptions for elderly persons in primary care is inappropriate.

Deprescribing is a complex process that is required for the safe and effective cessation of inappropriate medications. ${ }^{31}$ Systematic reviews of medication withdrawal trials (deprescribing) show that reducing specific classes of medicines, especially psychotropic and anticholinergic drugs, may decrease adverse events and improve the quality of life. ${ }^{32}$ Shared decision-making should be an integral part of the deprescribing process. ${ }^{33}$

The present study demonstrates that a Barthel index of $\leq 60$, rather than age, increased the odds of receiving a potentially inappropriate prescription. The Barthel index is the most widely used scale to evaluate activities of daily living and is scored from 0 to 100 points; scores $<60$ points indicate moderate-to-severe physical impairment. ${ }^{34}$ Older disabled adults, who often have complex comorbidities that require the prescription of multiple medications, may be highly susceptible to PIM use. Yang PJ et $\mathrm{al}^{35}$ revealed a high frequency of PIMs (94/141, 66.7\%) detected by the Beers 2012 criteria in disabled (Barthel index $\leq 60$ ) older patients, which was higher than the prevalence rates reported in previous studies. Benzodiazepines and hypnotics were the most commonly prescribed PIMs in disabled older patients.

Several limitations should be noted in the present study. First, it was a retrospective, single-center study. Second, only hospitalized patients were included and they were not representative of older, community-dwelling patients. Finally, the consequences of PIMs were not analyzed.

\section{Conclusion}

Our study described a high prevalence of polypharmacy and PIMs in hospitalized older patients. PIMs defined by the Beers 2015 criteria were shown to be associated with excessive polypharmacy, a Barthel index of $\leq 60$, and length of the hospital stay. The Beers 2015 criteria detected significantly more PIMs than the 2012 criteria due to the inclusion of PPIs. The updated Beers criteria provide a valuable tool to guide prescription in older adults.

\section{Acknowledgments}

Financial support for this work was received from the National Natural Science Foundation of China (81373487).

\section{Disclosure}

The authors report no conflicts of interest in this work.

\section{References}

1. Obreli-Neto PR, Nobili A, de Oliveira Baldoni A, et al. Adverse drug reactions caused by drug-drug interactions in elderly outpatients: a prospective cohort study. Eur J Clin Pharmacol. 2012;68(12): 1667-1676.

2. Fick DM, Cooper JW, Wade WE, Waller JL, Maclean JR, Beers MH. Updating the Beers criteria for potentially inappropriate medication use in older adults: results of a US consensus panel of experts. Arch Intern Med. 2003;163(22):2716-2724.

3. Qato DM, Alexander GC, Conti RM, Johnson M, Schumm P, Lindau ST. Use of prescription and over-the-counter medications and dietary supplements among older adults in the United States. JAMA. 2011; 300(24):2867.

4. Laroche ML, Charmes JP, Nouaille Y, Picard N, Merle L. Is inappropriate medication use a major cause of adverse drug reactions in the elderly? Br J Clin Pharmacol. 2007;63(2):177-186.

5. Spinewine A, Schmader KE, Barber N, et al. Appropriate prescribing in elderly people: how well can it be measured and optimised? Lancet. 2007;370(9582):173-184.

6. Cahir C, Fahey T, Teeling M, Teljeur C, Feely J, Bennett K. Potentially inappropriate prescribing and cost outcomes for older people: a national population study. Br J Clin Pharmacol. 2010;69(5):543-552.

7. Pedrós C, Formiga F, Corbella X, et al. Adverse drug reactions leading to urgent hospital admission in an elderly population: prevalence and main features. Eur J Clin Pharmacol. 2016;72(2):219-226.

8. Jyrkkä J, Enlund H, Korhonen MJ, Sulkava R, Hartikainen S. Polypharmacy status as an indicator of mortality in an elderly population. Drugs Aging. 2009;26(12):1039-1048.

9. Fu AZ, Jiang JZ, Reeves JH, Fincham JE, Liu GG, Perri M 3rd. Potentially inappropriate medication use and healthcare expenditures in the US community-dwelling elderly. Med Care. 2007;45(5):472-476.

10. Beers MH, Ouslander JG, Rollingher I, Reuben DB, Brooks J, Beck JC. Explicit criteria for determining inappropriate medication use in nursing home residents. UCLA Division of Geriatric Medicine. Arch Intern Med. 1991;151(9):1825-1832.

11. Rongen S, Kramers C, O'Mahony D, Feuth TB, Olde Rikkert MG, Ahmed AI. Potentially inappropriate prescribing in older patients admitted to psychiatric hospital. Int J Geriatr Psychiatry. 2016;31(2):137-145.

12. American Geriatrics Society 2015 Beers Criteria Update Expert Panel. American Geriatrics Society 2015 updated Beers criteria for potentially inappropriate medication use in older adults. $J$ Am Geriatr Soc. 2015;63(11):2227-2246.

13. Jano E, Aparasu RR. Healthcare outcomes associated with Beers' criteria: a systematic review. Ann Pharmacother. 2007;41(3):438-447.

14. Jirón M, Pate V, Hanson LC, Lund JL, Jonsson Funk M, Stürmer T. Trends in prevalence and determinants of potentially inappropriate prescribing in the United States: 2007 to 2012. J Am Geriatr Soc. 2016; 64(4):788.

15. Dalleur O, Boland B, De Groot A, et al. Detection of potentially inappropriate prescribing in the very old: cross-sectional analysis of the data from the BELFRAIL observational cohort study. BMC Geriatr. 2015; 15(1):156.

16. Mo L, Yang X, He J, Dong B. Evaluation of potentially inappropriate medications in older inpatients in China. J Am Geriatr Soc. 2014;62(11): 2216-2218.

17. Li H, Pu S, Liu Q, et al. Potentially inappropriate medications in Chinese older adults: the Beers criteria compared with the screening tool of older persons' prescriptions criteria. Geriatr Gerontol Int. Epub 2017 Feb 22.

18. Kimura T, Ogura F, Yamamoto K, et al. Potentially inappropriate medications in elderly Japanese patients: effects of pharmacists' assessment and intervention based on Screening Tool of Older Persons' Potentially Inappropriate Prescriptions criteria ver.2. J Clin Pharm Ther. 2016;42(2):209-214. 
19. Mulkerrin E, Epstein FH, Clark BA. Aldosterone responses to hyperkalemia in healthy elderly humans. J Am Soc Nephrol. 1995;6(5): 1459-1462.

20. Turgutalp K, Bardak S, Helvacı I, et al. Community-acquired hyperkalemia in elderly patients: risk factors and clinical outcomes. Ren Fail. 2016;38(9):1405-1412.

21. Janarthanan S, Ditah I, Adler DG, Ehrinpreis MN. Clostridium difficileassociated diarrhea and proton pump inhibitor therapy: a meta-analysis. Am J Gastroenterol. 2012;107(7):1001-1010.

22. Thaler HW, Sterke CS, van der Cammen TJ. Association of proton pump inhibitor use with recurrent falls and risk of fractures in older women: a study of medication use in older fallers. J Nutr Health Aging. 2016;20(1):77-81.

23. Lazarus B, Chen Y, Wilson FP, et al. Proton pump inhibitor use and the risk of chronic kidney disease. JAMA Intern Med. 2016;176(2): 238-246.

24. Yu LY, Sun LN, Zhang XH, et al. A review of the novel application and potential adverse effects of proton pump inhibitors. Adv Ther 2017;34(5):1070-1086.

25. San-José A, Agustí A, Vidal X, et al; Potentially Inappropriate Prescription in Older Patients in Spain (PIPOPS) Investigators' project. Inappropriate prescribing to the oldest old patients admitted to hospital: prevalence, most frequently used medicines, and associated factors. BMC Geriatr. 2015;15:42.

26. Hanlon JT, Semla TP, Schmader KE. Alternative medications for medications in the use of high-risk medications in the elderly and potentially harmful drug-disease interactions in the elderly quality measures. J Am Geriatr Soc. 2015;63(12):e8-e18.

27. Tannenbaum C, Martin P, Tamblyn R, Benedetti A, Ahmed S. Reduction of inappropriate benzodiazepine prescriptions among older adults through direct patient education: the EMPOWER Cluster Randomized Trial. JAMA Intern Med. 2014;174(6):890.
28. Hilmer SN, Gnjidic D. The effects of polypharmacy in older adults. Clin Pharmacol Ther. 2009;85(1):86-88.

29. Hudhra K, García-Caballos M, Casado-Fernandez E, Jucja B, Shabani D, Bueno-Cavanillas A. Polypharmacy and potentially inappropriate prescriptions identified by Beers and STOPP criteria in co-morbid older patients at hospital discharge. J Eval Clin Pract. 2016;22(2): $189-193$.

30. Opondo D, Eslami S, Visscher S, et al. Inappropriateness of medication prescriptions to elderly patients in the primary care setting: a systematic review. PLoS One. 2012;7(8):e43617.

31. Hasler S, Senn O, Rosemann T, Neuner-Jehle S. Effect of a patient-centered drug review on polypharmacy in primary care patients: study protocol for a cluster-randomized controlled trial. Trials. 2015;16:380.

32. van der Cammen TJ, Rajkumar C, Onder G, Sterke CS, Petrovic M. Drug cessation in complex older adults: time for action. Age Ageing. 2014;43(1):20-25.

33. Jansen J, Naganathan V, Carter SM et al., Too much medicine in older people? Deprescribing through shared decision making. BMJ. 2016;353:i2893.

34. Lawton MP, Brody EM. Assessment of older people: self-maintaining and instrumental activities of daily living. Gerontologist. 1969;9(3) 179-186.

35. Yang PJ, Lee YT, Tzeng SL, et al. Potentially Inappropriate Prescribing in Disabled Older Patients with Chronic Diseases: A Screening Tool of Older Persons' Potentially Inappropriate Prescriptions versus Beers 2012 Criteria[J]. Medical Principles \& Practice. 2015;24(6):565-570.
Clinical Interventions in Aging

\section{Publish your work in this journal}

Clinical Interventions in Aging is an international, peer-reviewed journal focusing on evidence-based reports on the value or lack thereof of treatments intended to prevent or delay the onset of maladaptive correlates of aging in human beings. This journal is indexed on PubMed Central, MedLine,

\section{Dovepress}

CAS, Scopus and the Elsevier Bibliographic databases. The manuscript management system is completely online and includes a very quick and fair peer-review system, which is all easy to use. Visit http://www.dovepress. com/testimonials.php to read real quotes from published authors. 